$9-11-2015$

\title{
Impact Of Death-Related Television Programming On Advertising Evaluation
}

Priyamvadha Rangan

SUNY, Brockport

Surendra N. Singh

University of Kansas

Mark J. Landau

University of Kansas

Jungsil Choi

Cleveland State University, j.choi59@csuohio.edu

Follow this and additional works at: https://engagedscholarship.csuohio.edu/bus_facpub

Part of the Advertising and Promotion Management Commons, and the Marketing Commons How does access to this work benefit you? Let us know!

\section{Publisher's Statement}

This is an Author's Accepted Manuscript of an article published in the Journal of Advertising 09-11-2015, available online: http://www.tandfonline.com/doi/full/10.1080/

00913367.2015 .1077490

\section{Original Published Citation}

Rangan, P., Singh, S.N., Landau, M.J., \& Choi, J. (2015). Impact of death-related television programming on advertising evaluation. Journal of Advertising, 44(4), 326-337. doi:10.1080/00913367.2015.1077490

This Article is brought to you for free and open access by the Monte Ahuja College of Business at EngagedScholarship@CSU. It has been accepted for inclusion in Business Faculty Publications by an authorized administrator of EngagedScholarship@CSU. For more information, please contact library.es@csuohio.edu. 


\title{
Impact of Death-Related Television Programming on Advertising Evaluation
}

\author{
Priyamvadha Rangan \\ State University of New York at Brockport, Brockport, New York, USA
}

Surendra N. Singh and Mark J. Landau
University of Kansas, Lawrence, Kansas, USA

Jungsil Choi

Cleveland State University, Cleveland, Ohio, USA

\begin{abstract}
Programming that depicts or implies death constitutes a vital component of daily television broadcasts, yet the impact of such programming on the evaluation of embedded advertising remains unexplored. Using terror management theory, we propose that exposure to routine and commonplace death-related television programming will lead to the differential evaluation of ensuing advertisements depending on whether they are perceived to be of domestic or foreign origin, and that this effect is contingent on the nature of the death-related cognitions at play at the time of ad exposure. Further, the death-related program context effects on embedded advertising are unique-ads at the end, not the beginning, of the embedded pod are affected by programming content. Based on the empirical findings from four studies we identify the cognitive processes underlying consumers' ad evaluation, isolate the pod positions when context effects are observed, and suggest a framework for television commercial scheduling.
\end{abstract}

Violent television programming depicting or implying death is pervasive, be it in dramas or news (Parents Television Council 2013). Some programs on broadcast and cable

Address correspondence to Priyamvadha Rangan, School of Business Administration and Economics, SUNY Brockport, 350 New Campus Drive, Brockport, NY 14420. E-mail: prangan@brockport.edu

Priyamvadha Rangan ( $\mathrm{PhD}$, University of Kansas) is an assistant professor, School of Business Administration and Economics, State University of New York at Brockport.

Surendra N. Singh (PhD, University of Wisconsin, Madison) is a professor of marketing, Southwestern Bell Chair in Business, School of Business and Professor of Health Policy and Management, School of Medicine, University of Kansas.

Mark J. Landau (PhD, University of Arizona) is an associate professor, Department of Psychology, University of Kansas.

Jungsil Choi ( $\mathrm{PhD}$, University of Kansas) is an assistant professor, Department of Marketing, Monte Ahuja College of Business, Cleveland State University. channels show an act of violence every two minutes, and $70 \%$ of the violence includes, among other things, corpses, mutilation, graphic killings, and suicide (Parents Television Council 2013). Further, local news shows (viewed by three out of four U.S. adults) devote $17 \%$ of news coverage to crime and $13 \%$ to accidents and disasters (State of the News Media 2013), often including information relating to fatalities. Yet it is not known how such prevalent and widely viewed programming will impact the evaluation of the ads in an ensuing commercial pod (i.e., a group of ads broadcast in a commercial break within a television program).

Extant predictions on the influence of death-depicting programming content on embedded advertising are mixed. Some researchers (Arndt et al. 2004) surmise that death-depicting programs will likely impact the evaluation of the embedded commercials, while others (Liu and Smeesters 2010) state that such programming will not influence the embedded ad evaluation. Given the plethora of death-depicting television programming, and the paucity of research investigating such programs' influence on the evaluation of embedded advertising, advertisers cannot make informed judgments on whether to advertise in such programs, and if they do, whether they should strategically schedule ads for telecast in specific pod positions to optimize advertising effectiveness. A review of the limited program context research — we found only 22 studies $^{1}$ in the advertising and marketing literature-shows that nonviolent television programs exert their maximal influence on the ads at the beginning of the embedded pod (Murry, Lastovicka, and Singh 1992), but death-related program context effects on advertising evaluation remain unexplored. Our research addresses this gap in the literature.

This research (a) explores whether death-related programming will have an impact on the evaluation of the ensuing advertisements, (b) identifies when the program context effects 
will be observed, and (c) proposes a process mechanism for these effects. We examine these issues using terror management theory (Greenberg, Pyszczynski, and Solomon 1986), which suggests that reminders of mortality make it salient and the intrinsic knowledge of the inevitability of death induces the potential for existential anxiety in humans. People mitigate mortality concerns by reinforcing their cultural beliefs and strongly defending the ideas, objects, peoples, and values that uphold their cultural worldviews - in other words, the cultural beliefs and ideologies of the group(s) with which they identify-and/or derogate those that do not. Further, the defense of the worldview occurs most reliably after a brief period of delay (Greenberg et al. 1994). We contend that information about an advertised brand's country of origin (domestic versus foreign) can signal to consumers whether the brand belongs to their in-group ${ }^{2}$ or out-group. Applying terror management theory to advertising, then, exposure to death-depicting television programs should lead television audiences to relieve their mortality concerns by biasing their evaluation of the ensuing commercials depending on whether they perceive the ads as being for brands of domestic (in-group) or foreign (out-group) origin. A priori, however, it is not known whether watching a commonplace death-depicting television program will induce mortality concerns to begin with, such that people subsequently alleviate these concerns by biasing their evaluations of the ensuing advertising.

Our findings from four studies identify and highlight the unique nature of death-depicting program context effects. Death-depicting programs indeed trigger death-related thoughts, and these thoughts systematically vary across a typical commercial pod-from being conscious to nonconscious but accessible (Study 1). Also, advertisements that appear toward the end of the pod are most influenced by the deathrelated program context (Studies 2 and 4). Further, the context effects are not a result of program-induced arousal or mood, which are currently explanatory variables for other nonviolent program context effects (Study 3). We begin with a review of germane research on terror management theory and its effects. Next, we sequentially develop our hypotheses. Then, we describe the methods and report the results from four studies. Finally, we discuss the theoretical and practical implications of our findings, research limitations, and directions for further research.

\section{THEORETICAL BACKGROUND}

\section{Impact of Mortality Concerns on Cognition: Proximal and Distal Defenses}

Terror management theory (Greenberg, Pyszczynski, and Solomon 1986) posits that humans' innate desire for perpetual life, coupled with their awareness of their mortality, creates the potential for existential anxiety. Exposure to death-depicting stimuli reminds individuals of their mortality (i.e., causes mortality salience; hereafter, MS), heightening the potential for angst. Moreover, reminders of mortality evoke deathrelated thoughts that are initially in conscious focus but gradually recede from focal attention yet remain accessible (Arndt et al. 1997). This variability in death-related thoughts changes the nature of cognitive defenses erected against mortality concerns. Specifically, conscious death-related thoughts trigger proximal defenses and nonconscious ones evoke distal defenses (Pyszczynski, Greenberg, and Solomon 1999). Proximal defenses are a direct and rational attempt to remove conscious death-related thoughts from focal attention via thought suppression and by biasing the inferential processes to deny vulnerability to death (Arndt, Allen, and Greenberg 2001). People biased their self-reports on whether they felt high or low levels of emotionality depending on what level they were told was related to a predisposition toward premature death (Greenberg et al. 1993). Denial of death vulnerability emerged when the cognitive bias measures were taken immediately after the MS induction (Greenberg et al. 1993).

In contrast, distal defenses occur most reliably after a brief period of delay during which time death-related cognitions recede from conscious awareness but remain accessible (Greenberg et al. 1994). Distal defenses do not directly address mortality concerns. Rather, they protect individuals from the potential for terror arising from the unconscious, innate knowledge of their inevitable demise. People protect themselves from the potential for anxiety by viewing themselves as valuable contributors to a meaningful world that transcends mortality, thereby allowing them to achieve a sense of symbolic immortality. They do this by (a) bolstering faith in their worldview with the enhanced positive (negative) evaluation of objects, peoples, and values that uphold (contradict) their cultural worldview and (b) striving for self-esteem, which is acquired by adopting the worldview (Pyszczynski, Greenberg, and Solomon 1999). Further, worldview defense manifests by augmenting in-group favorability and/or out-group derogation. Critically, proximal and distal defenses are operant only in their intended domains.

\section{Mortality Salience Effects in a Death-Related Television Program Context}

Using epochal death-related programming (in this case, September 11 terror attacks and plane crash videos), Liu and Smeesters (2010) found a stronger preference for a domestic brand over a foreign one in a death-related (versus neutral) media context, with domestic brand preference lasting even after 24 hours. They identify patriotism as the explanatory variable for these effects. However, no MS effects were found for ad liking. The authors state that MS-related effects will not be found for ad evaluation because MS-inducing programs do not affect mood, and it is program-induced mood that influences ad evaluation. 
We, on the other hand, argue that MS-related effects will, in fact, be observed for ad evaluation because factors other than mood can influence the evaluation of ads embedded within a television program (for review, see online Appendix 1). We posit that because television programming is vivid, the pattern of death-related thoughts that is elicited among the viewers, and the concomitant onset of proximal/distal defenses in a death-related television program viewing scenario, will be different from that observed in other MS research that typically uses different stimuli (e.g., physical proximity to funeral home) or tasks (e.g., death-related writing, completion of fearof-death scales) to make mortality salient (for review, see Pyszczynski, Greenberg, and Solomon 2005). Next, we make predictions on how and when death-related television programming will influence the ensuing ad evaluation.

For the purposes of our study, we divided a typical commercial pod (four-minute duration with eight commercials of 30 seconds each) into three parts to assess the nature of thoughts triggered at (1) the beginning of the pod $\left(\mathrm{MS}_{\mathrm{BEG}}\right)$ immediately after program exposure and just before the start of the first commercial in the pod; (2) the middle of the pod $\left(\mathrm{MS}_{\mathrm{MID}}\right)$-after viewing 1.5 minutes of filler commercials; and (3) the end of the pod $\left(\mathrm{MS}_{\mathrm{END}}\right)$ - just before exposure to the last commercial in the pod, that is, after viewing 3.5 minutes of filler commercials. Immediately after exposure to the MS-evoking information (at the beginning of the pod) we expect the number of conscious death-related thoughts to be high as a consequence of priming due to the programming content. Once the participants begin viewing the commercials, the priming effect should dissipate and participants should engage in thought suppression in reaction to their conscious thoughts of mortality, such that the number of death-related thoughts decreases by the middle of the pod. Also, the number of death-related thoughts at the middle of the pod should be comparable to that following exposure to a neutral program, because a neutral program contains no death-related information and so we do not expect death-related thoughts to be evinced through program exposure. By the end of the pod, the death-related thoughts should have receded from focal attention due to the delay and distraction caused by exposure to intervening commercials, such that the number of deathrelated thoughts is low and comparable to that following a neutral program. Specifically, we posit:

\footnotetext{
H1a: Compared to a neutral program, the number of death-related thoughts following a death-related program will be higher at the beginning of the pod $\left(\mathrm{MS}_{\mathrm{BEG}}\right)$ position.
}

Only when death-related thoughts are in conscious focus will people deny vulnerability to death as a proximal defense, enabling them to rationally view death as a problem for the distant future (Greenberg et al. 2000). We expect death-vulnerability denial to be elicited immediately after exposure to death-related information, that is, at the beginning of the pod and potentially up to the middle of the pod, when death-related thoughts are in conscious focus. But by the end of the pod, people should have stopped thinking about death due to the intervening commercials, and proximal defense via vulnerability denial will be minimal. Further, no death-vulnerability denial will be observed following a neutral program, as no mortality concerns will be triggered by program content. Thus:

H1b: Death-vulnerability denial will be exhibited only following a death-related program and at the beginning of the pod $\left(\mathrm{MS}_{\mathrm{BEG}}\right)$ position and up to the middle of the pod $\left(\mathrm{MS}_{\mathrm{MID}}\right)$ position.

If proximal defenses attenuate at the end of the pod, deathrelated thoughts are not in conscious awareness at the point. Further, only nonconscious death-related thoughts are associated with distal defenses of the cultural worldview (Pyszczynski, Greenberg, and Solomon 1999). Information about an advertised brand's country of origin (domestic versus foreign) informs consumers whether the brand belongs to their in-group or out-group. We posit that nonconscious death-related thoughts triggered by an MS-inducing program will make participants prefer an in-group ad (for a product perceived to be of domestic country of origin) over an out-group ad (for a product perceived to be of foreign country of origin) only at the end of the pod. Also, nonconscious death-related thoughts should mediate the relationship between program context (i.e., control versus $\mathrm{MS}_{\mathrm{END}}$ ) and ad evaluation by either enhancing domestic ad evaluation or diminishing foreign ad evaluation. Specifically:

H2a: Ad evaluation of a foreign ad will be lower than that for a domestic ad only at the end of the pod $\left(\mathrm{MS}_{\mathrm{END}}\right)$ position following a death-related program.

H2b: Nonconscious death-related thoughts will mediate the relationship between program context and ad evaluation.

\section{STUDY 1: TRACKING DEATH-RELATED THOUGHTS IN A COMMERCIAL POD}

Study 1 examines whether mundane death-related television programming triggers death-related thoughts, and whether these thoughts vary over the ensuing pod. We used a six-level (five treatment levels plus control) between-subjects design, where MS was manipulated and the effects measured at different pod positions to simulate five MS conditions: beginning of the pod $\left(\mathrm{MS}_{\mathrm{BEG}}\right)$ versus after exposure to one commercial ( $\mathrm{MS}+1 \mathrm{ad})$ versus after exposure to two commercials ( $\mathrm{MS}+2 \mathrm{ads}$ ) versus middle of the pod $\left(\mathrm{MS}_{\mathrm{MID}}\right)$ versus end of the pod $\left(\mathrm{MS}_{\mathrm{END}}\right)^{3}{ }^{3}$ The control group watched neutral programming without death-related content. Table 1 gives the treatment schema of video stimuli for all the studies.

Participants $(N=177)$ completed the study for course credit. The participants in all the studies of this research were native English-speaking American students who participated 
TABLE 1

Treatment Schema for Video Clips Across Studies

\begin{tabular}{|c|c|c|c|}
\hline Studies & TV Program Conditions & Video Content & Video Duration \\
\hline \multirow[t]{6}{*}{1 and 2} & $\mathrm{MS}_{\mathrm{BEG}}$ & MS news clip & 5 minutes \\
\hline & $\mathrm{MS}+1 \mathrm{ad}$ & MS news clip +1 filler ad & 5 minutes, 30 seconds \\
\hline & $\mathrm{MS}+2$ ads & MS news clip +2 filler ads & 6 minutes \\
\hline & $\mathrm{MS}_{\mathrm{MID}}$ & MS news clip +3 filler ads & 6 minutes, 30 seconds \\
\hline & $\mathrm{MS}_{\mathrm{END}}$ & MS news clip +7 filler ads & 8 minutes, 30 seconds \\
\hline & Control & Control news clip & 5 minutes \\
\hline \multirow[t]{2}{*}{3} & $\mathrm{MS}_{\mathrm{END}}$ & MS news clip +7 filler ads & 8 minutes, 30 seconds \\
\hline & Control & Control news clip & 5 minutes \\
\hline \multirow[t]{4}{*}{4} & $\mathrm{MS}_{\mathrm{MID}}$ & MS news clip +3 filler ads & 6 minutes, 30 seconds \\
\hline & $\mathrm{MS}+5 \mathrm{ads}$ & MS news clip +5 filler ads & 7 minutes, 30 seconds \\
\hline & $\mathrm{MS}_{\mathrm{END}}$ & MS news clip +7 filler ads & 8 minutes, 30 seconds \\
\hline & Control & Control news clip & 5 minutes \\
\hline
\end{tabular}

Note $. \mathrm{MS}=$ mortality salience; $\mathrm{MS}_{\mathrm{BEG}}=$ beginning of the pod; $\mathrm{MS}_{\mathrm{MID}}=$ middle of the pod; $\mathrm{MS}_{\mathrm{END}}=$ end of the pod.

for course credit, as this research examined cultural worldview defense by pitting an American brand against a foreign one, and required the participants to complete English languagerelated tasks.

The program stimuli were newscasts recorded and edited from a local affiliate. The first 3.5 minutes of both the MS and control clips were identical, covering current affairs. The last 1.5 minutes of the MS news clip covered crimes or accidents with fatalities in the neighborhood, whereas the control news clip covered sports. Due to its time-sensitive nature, news clips were recorded and edited just before this and each subsequent study. Depending on the MS condition, the MS news clip was followed by a commercial pod that varied in the number of filler ${ }^{4}$ commercials it contained. Poncin and Derbaix (2009) found that feelings induced by prior commercials in a pod influenced the evaluation of later commercials. Filler commercials were selected through pretests that addressed the potential confound of commercial-induced affect. There were three and seven filler commercials in the middle of the pod and end of the pod conditions, respectively. No filler commercials were used in the beginning of the pod and control conditions; the control news clip had no MS-inducing information and so we expected death-related thoughts to remain the same irrespective of the number of ads that followed the control video.

As part of a television-viewing study, participants initially watched the news video on lab computers and then wrote down all the thoughts that came to mind following Greenberg and colleagues (1994). Phrases containing death-related words were tallied to obtain the thought-listing measure. Next, ostensibly as part of a personality study, participants provided death-vulnerability denial reports by completing the Emotional Lability Inventory questionnaire (Greenberg et al. 2000). Half of the participants read that a study published in a medical journal had established that individuals high in emotional lability (frequency of change in emotions) die at an early age. The other half read that people low in emotional lability die early. The participants then responded to 24 items on the extent to which they experienced different emotions in a time period on an 11-point scale $(1=$ Never experiencing the emotion; $11=$ Experiencing the emotion virtually all the time). Some of the questions were "How often do you feel your heart pounding?"; "How often do you feel joyous?"; "How often do you raise your voice above its normal level?"; and "How often do you feel scared?" This gave participants the opportunity to bias their responses about emotional lability and thus vulnerability to premature death. Self-reports could be either low or high based on initial brief, and scores reflected death-vulnerability denial - the cognitive bias from consciously thinking of the result of their ratings when the measure was taken (Greenberg et al. 2000). Finally, the participants completed the Positive and Negative Affect Schedule (PANAS) scale (Watson, Clark, and Tellegen 1988).

\section{Results}

Thought listing. Number of death-related thoughts in the control condition $\left(M_{\mathrm{CON}}=.07\right)$ was significantly lower than at (a) beginning of the pod $\left(M_{\mathrm{BEG}}=1.83\right.$, Dunnett's $t(4,171)=8.60, p<.001)$; (b) after exposure to one ad $\left(M_{1}=1.24\right.$, Dunnett's $\left.t(4,171)=5.95, p<.001\right)$, and $(\mathrm{c})$ after exposure to two ads $\left(M_{2}=1.0\right.$, Dunnett's $t(4,171)=$ $4.85, p<.001)$. Further, number of death-related thoughts in the control condition was similar to that at (a) middle of the $\operatorname{pod}\left(M_{\mathrm{MID}}=.52\right.$, Dunnett's $\left.t(4,171)=2.29, p=.095\right)$ and (b) end of the pod $\left(M_{\mathrm{END}}=.47\right.$, Dunnett's $t(4,171)=2.05$, $p=.161)$. Hypothesis 1a was supported.

Death-vulnerability denial. A 6 program context $\left(\mathrm{MS}_{\mathrm{BEG}}\right.$ versus $M S+1$ ad versus $M S+2$ ads versus $M_{\text {MID }}$ versus $\mathrm{MS}_{\mathrm{END}}$ versus control) $\times 2$ emotionality information (high versus low) analysis of variance (ANOVA) on the composite 
emotional lability score (average of the 24 items; $\alpha=.88$ ) revealed a main effect for emotionality $\left(M_{\mathrm{HIGH}}=5.25\right.$ versus $\left.M_{\text {LOW }}=5.83 ; F(1,165)=19.52, p<.001\right)$. The participants who were informed that highly emotional people die young reported lower lability than those told that unemotional people die young; participants in both emotionality groups biased their reports to indicate that they were not the type of person with a short life expectancy. This was qualified by a significant interaction effect $(F(5,165)=2.88, p=.016)$. Participants did not bias their emotional lability reports and were not concerned about life expectancy in the control condition $\left(M_{\mathrm{HIGH}}=5.52\right.$ versus $\left.M_{\mathrm{LOW}}=5.60 ; F(1,165)=.059, p=.81\right)$ and at the end of the pod $\left(M_{\mathrm{HIGH}}=5.61\right.$ versus $M_{\mathrm{LOW}}=5.41 ; F(1,165)$ $=.41, p=.523)$; death-vulnerability denial was not exhibited. But there were significant differences in participants' selfreports in all the other MS conditions ( $p s<.037$ ); participants denied their vulnerability to death at the beginning of the pod and continued to do so up to the middle of the pod (refer to online Appendix 2). The results supported hypothesis $1 \mathrm{~b}$.

Further, we computed a composite emotional lability index by reverse coding the ratings of those who were told that highly emotional people die young; high index ratings uniformly showed death-vulnerability denial. Contrasts between the index at the end of the pod and the other conditions showed that death-vulnerability denial at the end of the pod $\left(M_{\mathrm{END}}=\right.$ $5.83)$ was lower than denial at (a) beginning of the pod $\left(M_{\mathrm{BEG}}\right.$ $=6.65$, Dunnett's $t(4,171)=3.18, p=.009)$, (b) after exposure to one ad $\left(M_{1}=6.53\right.$, Dunnett's $t(4,171)=2.71$, $p=.032)$, (c) after exposure to two ads $\left(M_{2}=6.48\right.$, Dunnett's $t(4,171)=2.58, p=.046)$, and (d) middle of the pod $\left(M_{\mathrm{MID}}\right.$ $=6.50$, Dunnett's $t(4,171)=2.60, p=.046)$, and comparable to vulnerability denial in the control condition $\left(M_{\mathrm{CON}}=\right.$ 6.01 , Dunnett's $t(4,171)=.69, p=.941)$. People who completed the denial measures immediately after the MS induction reported higher emotionality (showing they did not have short life expectancy) compared to those in the control condition and those who completed the measures after watching more than three minutes of ads.

Affect. ANOVA results on the positive $(\alpha=.85 ; F(5,171)$ $=1.139, p=.342)$ and negative $(\alpha=.70 ; F(5,171)=1.01$, $p=.417)$ components of the PANAS scale did not differ significantly across the different MS and control conditions.

\section{Discussion}

The thought-listing activity showed that immediately after exposure to death-related programming, and following exposure to the first and second commercials, the number of deathrelated thoughts was high: people were consciously processing death-related information. Thought-suppression efforts kicked in by the middle of the pod; the number of death-related thoughts was low and comparable to the control condition. By the end of the pod, if death-related thoughts had still been in conscious awareness, the number of listed death-related thoughts would have been higher than in the control condition; the intervening commercials would have distracted the respondents and attenuated thought-suppression efforts. Instead, the number of death-related thoughts listed was low. We therefore infer that death-related thoughts were not in focal attention at the end of the pod. The death-vulnerability data provided further corroboration. Denial of a short life occurs when death-related thoughts are conscious (Greenberg et al. 2000). Death-vulnerability denial was observed up to the middle of the pod; death-related thoughts were of a conscious nature at the front end of the pod following death-related programming. By the end of the pod, the death-vulnerability denial scores were low and comparable to the neutral program; death-related cognitions had largely receded from focal attention.

It is crucial to note that other mortality salience-related studies (unlike ours) find the number of death-related thoughts in the immediate condition to be low and comparable to the neutral condition (e.g., Greenberg et al. 1994). This is likely due to two reasons: First, those studies typically manipulate mortality salience with semantic priming, whereas we used a five-minute television program in which the last 90 seconds had death-related audiovisual information, explicit and more vivid, probably creating strong priming. Second, other studies had participants complete a mood scale immediately following the MS manipulation before measuring death-related thoughts; the delay and distraction due to the mood measure could attenuate the amount of reported death-related thoughts. In our study, death-related thoughts were measured immediately after the MS manipulation to reduce the confounding effects of intervening measures and to replicate a real-world television setting. We suggest that the middle of the pod condition in our television study is comparable to the immediate condition reported in other nontelevision MS studies.

In sum, Study 1 results support the notion that death-related thoughts remain in conscious focus up to the middle of the pod but recede from consciousness by the end of the pod. Because death-related thoughts are not in focal attention at the end of the pod, distal defenses, if any, should manifest only at the end of the pod. From an advertising perspective, an ad for a domestic (foreign) product will be perceived to belong to the ingroup (out-group). Cultural worldview defense in the form of differential evaluation of the foreign (versus domestic) ad should therefore be observed following death-related programming toward the end of the pod, when death-related thoughts are nonconscious. We investigate this in Study 2.

\section{STUDY 2: DISTAL MORTALITY SALIENCE EFFECTS WITHIN A POD}

We examine the impact of death-related programming on ads in different pod positions to ascertain when distal defense of the cultural worldview will and will not occur. In a 5 (MS conditions: beginning of the pod $\left(\mathrm{MS}_{\mathrm{BEG}}\right)$ versus after 
exposure to one commercial (MS+1 ad) versus after exposure to two commercials ( $\mathrm{MS}+2$ ads) versus middle of the pod $\left(\mathrm{MS}_{\mathrm{MID}}\right)$ versus end of the pod $\left.\left(\mathrm{MS}_{\mathrm{END}}\right)\right) \times 2$ (ad type: foreign versus domestic) +2 (control condition: foreign versus domestic) between-subjects design, 302 students, less two outliers, participated in the study. The news clips were similar to Study 1 . Two ads were developed ${ }^{5}$ for a fictitious brand of digital camera that varied only in the country-of-origin information in the headline. The level of activation of death-related thoughts has been measured with great reliability (Hayes et al. 2010) by indirect procedures that capture death-thought accessibility (DTA), which is measured by having participants complete a 20-word fragment list (six words can be completed as either neutral or death-related words, e.g., $\mathrm{COFF}_{--}=$coffee or coffin; Greenberg et al. 1994). The higher the number of death-related words completed, the higher the DTA. As part of a television study, participants initially watched the news video and completed the DTA measures. ${ }^{6}$ Next, as part of an advertising study, they read one of the target ads and completed measures for attitude toward the ad (five-item, 7-point scale; 1 = Bad/not likable/uninformative/not useful/unpleasant $; 7=$ Good/likeable/informative/useful/pleasant $; \alpha=.76$; Forehand and Deshpande 2001) and attitude toward the brand (four-item, 7-point scale; $1=$ Bad/negative/unfavorable/low quality; $7=$ Good/positive/favorable/high quality; $\alpha=.85$; Swaminathan, Page, and Gurhan-Canli 2007).

\section{Results}

Death thought accessibility. Only a significant program context main effect $(F(5,288)=4.61, p<.001)$ was observed; DTA scores were significantly different in the control and MS conditions (Table 2). Planned contrasts showed that DTA in the control condition $\left(M_{\mathrm{CON}}=1.26\right)$ was comparable to DTA at the middle of the pod $\left(M_{\mathrm{MID}}=1.51, p\right.$ $=.217$ ) and significantly lower than DTA at (a) beginning of the pod $\left(M_{\mathrm{BEG}}=2.05, p<.001\right)$, (b) after exposure to one ad $\left(M_{1}=1.92, p=.001\right)$, (c) after exposure to two ads $\left(M_{2}=\right.$ $1.90, p=.002)$, and $(\mathrm{d})$ end of the pod $\left(M_{\mathrm{END}}=1.96, p=\right.$ $.001)$.

Attitude toward the ad. A significant interaction between ad type and treatment $(F(5,288)=2.86, p=.015)$ occurred. Post hoc analyses revealed that the foreign ad was evaluated significantly lower than the domestic ad only at the end of the $\operatorname{pod}(F(1,288)=7.5, p=.007)$; the evaluations of the foreign and domestic ads were equivalent $(p s>.14)$ in all other pod positions (Table 2), supporting hypothesis 2a. Moderated mediation analysis (Preacher, Rucker, and Hayes 2007) showed that nonconscious DTA mediated the relationship between program context and attitude toward the foreign ad $(z=-2.31, p=.021)$ but not attitude toward the domestic ad $(z=1.33, p=.185)$. Nonconscious DTA led to the lowered foreign ad evaluation at the end of the pod, supporting hypothesis $2 b$. Online Appendix 3 provides the indirect effect analysis (Preacher and Hayes 2004) of the relationship between program context (i.e., control versus $\mathrm{MS}_{\mathrm{END}}$ ) and foreign ad evaluation via nonconscious DTA for this study and Study 4.

Attitude toward the brand. A significant interaction between ad type and treatment $(F(5,288)=2.35, p=.041)$ was found; the data pattern was similar to attitude toward the ad. Post hoc analyses showed that the foreign brand was evaluated significantly lower than the domestic brand only at the end of the pod $(F(1,288)=5.86, p=.016)$; the evaluations of both brands were equivalent $(p s>.13)$ in the other pod positions. A multiple-step, multiple-mediator model (Hayes, Preacher, and Myers 2010) of the indirect effect of the program context on attitude toward the foreign brand, first through DTA and then via attitude toward the foreign ad, was

TABLE 2

DTA and Attitude Toward the Ad Results

\begin{tabular}{|c|c|c|c|}
\hline Studies & TV Program Conditions & DTA & Aad (Domestic versus Foreign) \\
\hline \multirow[t]{4}{*}{2} & $\mathrm{MS}_{\mathrm{BEG}}$ & 2.05 & 4.37 versus 4.61 \\
\hline & $\mathrm{MS}+1 \mathrm{ad}$ & 1.92 & 4.20 versus 4.52 \\
\hline & $\mathrm{MS}_{\mathrm{MID}}$ & 1.51 & 4.52 versus 4.18 \\
\hline & $\mathrm{MS}_{\mathrm{END}}$ & 1.96 & 4.82 versus 4.16 \\
\hline 3 & Control & 1.46 & $\mathrm{~N} / \mathrm{A}$ \\
\hline \multirow[t]{4}{*}{4} & $\mathrm{MS}_{\mathrm{MID}}$ & 1.54 & 3.66 versus 3.98 \\
\hline & $\mathrm{MS}+5$ ads & 2.09 & 3.84 versus 3.23 \\
\hline & $\mathrm{MS}_{\mathrm{END}}$ & 2.22 & 3.87 versus 3.15 \\
\hline & Control & 1.43 & 3.66 versus 3.88 \\
\hline
\end{tabular}

Note. $\mathrm{N} / \mathrm{A}=$ not applicable; $\mathrm{MS}=$ mortality salience; $\mathrm{MS}_{\mathrm{BEG}}=$ beginning of the pod; $\mathrm{MS}_{\mathrm{MID}}=$ middle of the pod; $\mathrm{MS}_{\mathrm{END}}=\mathrm{end}$ of the pod; DTA = Death thought accessibility; Aad = attitude toward the ad. 
significant; zero was not present in the $95 \%$ bootstrapped confidence interval $(-.32,-.04)$.

\section{Discussion}

Distal defense via lowered evaluation of the foreign ad was observed at the end of the pod when death-related thoughts were nonconscious (Study 1) but not at other pod positions. It is important to note that DTA was high at both the beginning of the pod and at the end of the pod. Indeed, death-related thoughts will be accessible when they are conscious and not suppressed and when they are nonconscious but accessible. As we discussed in the previous study, the nature of the television stimulus causes a priming effect, and it takes about a minute for people to engage in thought-suppression efforts, such that DTA becomes low and comparable to the control condition. The high DTA at the beginning of the pod is triggered by conscious thoughts of death, while the high DTA at the end of the pod is triggered by the nonconscious death-related thoughts (Study 1). Nonconscious DTA led to lowered foreign ad evaluation at the end of the pod. Further, the relationship between program context and attitude toward the foreign brand was mediated first through nonconscious DTA and then via attitude toward the foreign ad. But could these effects have been caused by other variables, such as program-induced affect or arousal, which we did not measure in Study 2? We conducted Study 3 to account for alternative explanations for the deathrelated program context effects observed in this study.

\section{STUDY 3: RULING OUT ALTERNATIVE INFLUENCES}

Prior television program context research (for review, see online Appendix 1) has identified both program-induced mood and arousal as causal factors for context effects. Also, regarding news programs in particular, researchers have suggested that news stories could trigger negative arousal (Grabe et al. 2000) or negative emotions (Murry and Dacin 1996), which could potentially color the death-related context effects that we found in Study 2. On the other hand, a consistent finding in MS-related literature is that MS effects are not a by-product of affect, arousal, or anxiety induced by exposure to MS-related stimuli (Pyszczynski, Greenberg, and Solomon 2005). The lack of arousal- or affect-related mediation in death-activated defenses is due to humans being aware that death is inevitable, unlike other fearful things; the defenses triggered by MS assuage the potential for existential anxiety, rather than the actual experience of anxiety (Greenberg et al. 2003). Study 3 was conducted to assimilate or rule out any affect- or arousalrelated alternative explanations for the distal MS effects at the end of the pod.

In a two level (program type: MS-end of the pod $\left(\mathrm{MS}_{\mathrm{END}}\right)$ versus control) between-subjects design, 57 participants first watched a news video (similar to previous studies). Following this, they completed two five-item arousal measures, namely tension arousal, a high-activation state (jittery, intense, fearful, clutched-up, tense; $\alpha=.79$ ), and energy arousal, a general activation state (active, energetic, vigorous, lively, full of pep; $\alpha=.85)$, measured on a 4-point scale $(1=$ Definitely do not feel; $4=$ Definitely feel) that has been used in prior advertising research (Potter et al. 2006; LaTour and Rotfeld 1997), a 5-point pictorial scale adapted from the Self-Assessment Mannequin measure that has been used to evaluate arousal to television messages (Lang, Potter, and Bolls 1999), DTA, PANAS, and task involvement (e.g., "I paid a lot of attention to the tasks in the study"; "I was very involved with the tasks in the study"; 1 = Strongly disagree; $5=$ Strongly agree; $\alpha=.7)$.

\section{Results}

Arousal. ANOVA showed no significant differences between groups for tension arousal $\left(M_{\mathrm{CON}}=1.58 ; M_{\mathrm{END}}=\right.$ $1.62 ; F(1,55)=.094, p=.761)$ and energy arousal $\left(M_{\mathrm{CON}}=\right.$ $\left.2.15 ; M_{\mathrm{END}}=2.19 ; F(1,55)=.079, p=.78\right)$. Further, an analysis of the self-assessment mannequin pictorial scale measure showed no significant differences $\left(M_{\mathrm{CON}}=3.25 ; M_{\mathrm{END}}\right.$ $=3.17 ; F(1,55)=.160, p=.69)$. Exposure to both deathrelated and neutral programs elicit comparable levels of arousal.

Death thought accessibility. ANOVA revealed a significant program context effect $\left(M_{\mathrm{CON}}=1.46 ; M_{\mathrm{END}}=2.31\right.$; $F(1,55)=11.406, p=.001)$; DTA scores were significantly higher at the end of the pod (versus control) condition, replicating Study 2's findings (Table 2).

Affect. Neither the positive $(F(1,55)=.009, p=.926)$ nor the negative $(F(1,55)=.838, p=.364)$ component of the PANAS scale was significantly different across conditions.

Involvement. Self-reports on involvement did not vary across both conditions $\left(M_{\mathrm{CON}}=3.73 ; M_{\mathrm{END}}=3.48 ; F(1,55)\right.$ $=1.5, p=.226$ ); people devoted the same amount of attention and engagement to their tasks in both the MS and control conditions.

\section{Discussion}

Arousal and affect did not vary following exposure to either the neutral or death-related program. These findings are consistent with prior research that suggests that MSeffects are not a by-product of affect, arousal or anxiety induced by exposure to MS stimuli (Pyszczynski, Greenberg, and Solomon 2005). The previous studies demonstrate that MS programming triggers mortality concerns and that distal MS effects of lowered foreign ad evaluation are observed only at the end of the pod. We can only surmise that somewhere between the middle and the end of the pod, death-related thoughts changed from being conscious but suppressed to becoming nonconscious but 
accessible, and triggered worldview defense. Study 4 investigated this.

\section{STUDY 4: ONSET OF DISTAL MS EFFECTS}

In this study, we examined whether death-related thoughts recede from consciousness at an intervening pod position between $\mathrm{MS}_{\mathrm{MID}}$ and $\mathrm{MS}_{\mathrm{END}}$ such that worldview defense might be observed sooner. We added an intermediate $\mathrm{MS}$ condition between $\mathrm{MS}_{\mathrm{MID}}$ and $\mathrm{MS}_{\mathrm{END}}$ (i.e., after exposure to five 30 -second ads $[\mathrm{MS}+5$ ads] or 2.5 minutes of filler ads) and tested whether distal MS effects would be observed at that position. To create a more realistic television viewing scenario, we created two 30-second commercials $^{7}$ for the same digital camera brand. The target commercial was viewed in the fourth spot or the sixth spot or the eighth spot immediately after DTA was obtained. We used a 3 (MS conditions: middle of the pod $\left(\mathrm{MS}_{\mathrm{MID}}\right)$ versus after exposure to five commercials $\left(\mathrm{MS}_{5}\right)$ versus end of the pod $\left.\left(\mathrm{MS}_{\mathrm{END}}\right)\right) \times 2$ (ad type: foreign versus domestic $)+2$ (control condition: foreign vs. domestic) between-subjects design with 230 participants. The videos and procedure were similar to Study 2, and the dependent measures were the same as in Study 2 with the addition of the PANAS scale from Study 1.

\section{Results}

Death thought accessibility. A two-way ANOVA ((program context: $\mathrm{MS}_{\mathrm{MID}}$ versus $\mathrm{MS}_{5}$ versus $\mathrm{MS}_{\mathrm{END}}$ versus control) $\times$ ad type: (domestic versus foreign)) revealed only a significant program context main effect $(F(3,222)=9.22$, $p<.001)$. DTA scores were significantly different in the control and MS conditions (Table 2). Contrasts showed that DTA in the control condition $\left(M_{\mathrm{CON}}=1.43\right)$ was comparable to DTA at the middle of the pod $\left(M_{\mathrm{MID}}=1.54, p=.571\right)$ but significantly lower than DTA following exposure to five ads $\left(M_{5}=2.09, p<.001\right)$ and at the end of the pod $\left(M_{\mathrm{END}}=\right.$ 2.22, $p<.001)$.

Attitude toward the ad. ANOVA showed a significant interaction effect $(F(3,222)=5.02, p=.002)$. Further, attitude toward the foreign ad was significantly lower than attitude toward the domestic ad after exposure to five ads $(F(1,222)=$ $6.46, p=.012)$ and the end of the pod $(F(1,222)=8.61$, $p=.004)$ but was similar $(p s>.19)$ in the other conditions (Table 2). Moderated mediation analyses confirmed that nonconscious DTA mediated the relationship between program context and attitude toward the foreign ad $\left(\mathrm{MS}_{5}: z=-3.02\right.$, $\left.p=.003 ; \mathrm{MS}_{\mathrm{END}}: z=-3.05, p=.002\right)$ but not the domestic ad $\left(\mathrm{MS}_{5}: z=.44, p=.659\right.$; $\left.\mathrm{MS}_{\mathrm{END}}: z=.89, p=.372\right)$, replicating Study 2 findings; nonconscious DTA led to lowered foreign ad evaluation toward the end of the pod.

Attitude toward the brand. The data pattern was similar to attitude toward the ad: attitude toward the foreign brand was lower than attitude toward the domestic brand after exposure to five ads $(F(1,222)=7.88, p=.005)$ and at the end of the pod $(F(1,222)=4.34, p=.038)$ but not in other conditions $(p s>.2)$. Multiple-step, multiple-mediator models confirmed that indirect effect of the program context on attitude toward the foreign brand, first through DTA and then via attitude toward the foreign ad, was significant both after exposure to five ads and at the end of the pod. Zero was not present in the $95 \%$ bootstrapped confidence interval $\left(\mathrm{MS}_{5}:-.38,-.02\right.$; $\left.\mathrm{MS}_{\mathrm{END}}:-.32,-.03\right)$.

Affect. Neither the positive $(F(7,222)=1.04, p=.402)$ nor the negative $(F(7,222)=.6, p=.757)$ component of the PANAS scale was significantly different across conditions.

\section{Discussion}

Death-related thoughts receded from conscious focus about 2.5 minutes after exposure to MS-evoking stimulus. After exposure to the fifth 30 -second commercial in the ensuing pod, distal defenses of the cultural worldview kicked in, leading to the subsequent lower evaluation of the foreign (versus domestic) ad. Consistent with Study 2, nonconscious DTA mediated the relationship between program context and attitude toward the ad, and attitude toward the brand.

\section{GENERAL DISCUSSION}

Although death-related television programming is pervasive, there has been no systematic investigation of how and when such programming content will influence the viewers' evaluation of the ensuing commercials. Four studies reported in the current research shed light on this topic. Drawing on terror management theory, we argued that if death-related television programming triggered death-related cognitions, then viewers would protect themselves from the potential for existential anxiety by biasing their evaluations of the embedded advertising. Specifically, we posited that when nonconscious death-related thoughts were accessible, there would be a differential evaluation of ads depending on whether they were perceived to be of domestic or foreign origin. We first examined whether routine and mainstream television programs (i.e., daily local news) portraying death-related content-unlike atypical programs depicting epochal events (e.g., September 11 terror attacks) - do, in fact, trigger death-related thoughts and investigated whether these thoughts transitioned from being conscious to nonconscious over an ensuing commercial pod (Study 1). Next, expanding the scope of our research, we determined the specific pod positions where MS effects would be found and identified a new process mechanism for the death-related program context effects (Studies 2 and 4) while ruling out alternative explanations (Study 3). We provide the schema of cognitive responses to death-related programming and their effects on ad evaluation in Figure 1. 


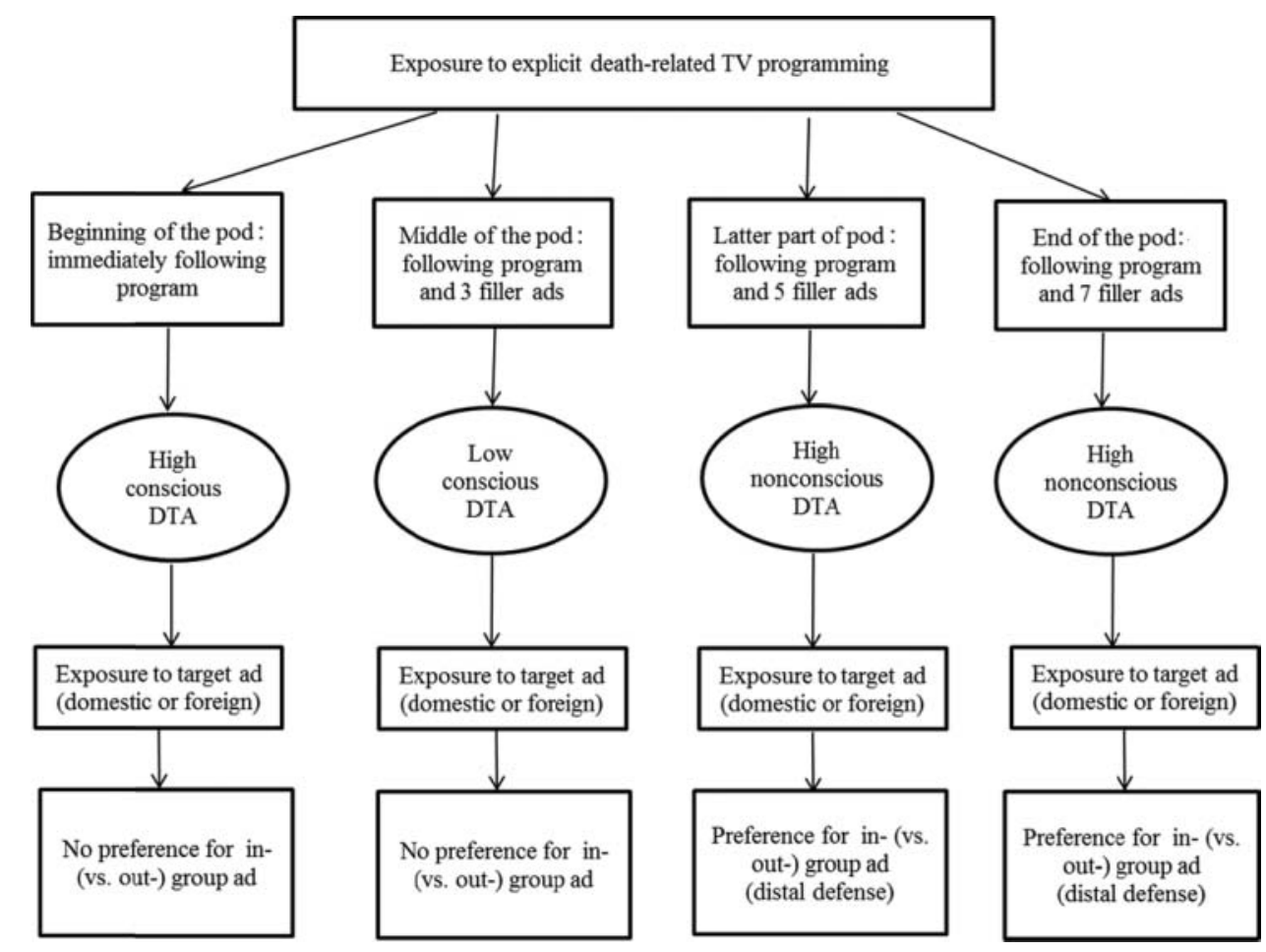

FIG. 1. The cognitive framework for consumer evaluation in a death-related program context. Note. DTA = death thought accessibility.

The current research attests to the importance and significance of death-related program context effects. Using different ad stimuli (print ads: Study 2; scratch commercial: Study 4) that varied only in the country-of-origin information, we found that MS-related distal effects manifest toward the end of the pod; ad evaluation varied depending on whether the ad flagged in-group or out-group membership to American participants. Worldview defense in the form of lowered foreign (versus domestic) ad evaluation was exhibited when death-related thoughts were nonconscious but accessible, and these effects manifested as early as 2.5 minutes after exposure to an MSinducing television program (Studies 2 and 4). Moreover, the relationship between program context and attitude toward the foreign ad was mediated by nonconscious DTA, and the diminished foreign brand evaluation resulted from both nonconscious DTA and the foreign ad evaluation.

To our knowledge, this research is the only attempt at exploring the nature of death-related thoughts evoked by death-related television programming. The four studies herein offer compelling evidence that cognitions triggered by MSinducing television programming are unique. MS-evoking programs triggered death-related thoughts that were in conscious focus at the beginning of the pod but receded from consciousness at the end of the pod. Importantly, immediately following exposure to death-related programming, the number of deathrelated thoughts (Study 1) and DTA (Study 2) was high. The observed pattern was different from research that uses other MS inductions, like semantic priming, where immediately following mortality reminders the number of death-related thoughts (and concomitant DTA, if measured) was low. But this was not unexpected, given the vividness of television stimuli and its priming effects. We found that it took more than one minute for people to engage in thought-suppression efforts, such that by the middle of the pod the number of death-related thoughts (Study 1) or DTA (Studies 2 and 4) receded to baseline levels comparable to the neutral condition. Toward the end of the pod, the number of listed death-related thoughts was low (Study 1), but DTA was high (Studies 2 and 4), replicating other research. In addition, while some researchers have suggested that news programs might elicit negative moods (Murry and Dacin 1996) or negative arousal (Grabe et al. 2000) that could influence subsequent ad evaluation, we found this is not the case; MS-related news programming triggered MS effects that were not a by-product of arousal or mood (Study 3).

This research draws attention to context effects in a television program genre that has been neglected in theory and practice. This research is the first attempt at highlighting the unique nature of death-related television program context effects: MS-inducing programming influences ads that appear toward the end of the ensuing commercial pod, contrary to other television programming that exerts its maximal influence on the ads that appear at the beginning of the pod (Murry, Lastovicka, and Singh 1992). Likewise, contrary to other programs' effects, death-related program context effects are not a result of program-induced mood or arousal. In addition, we 


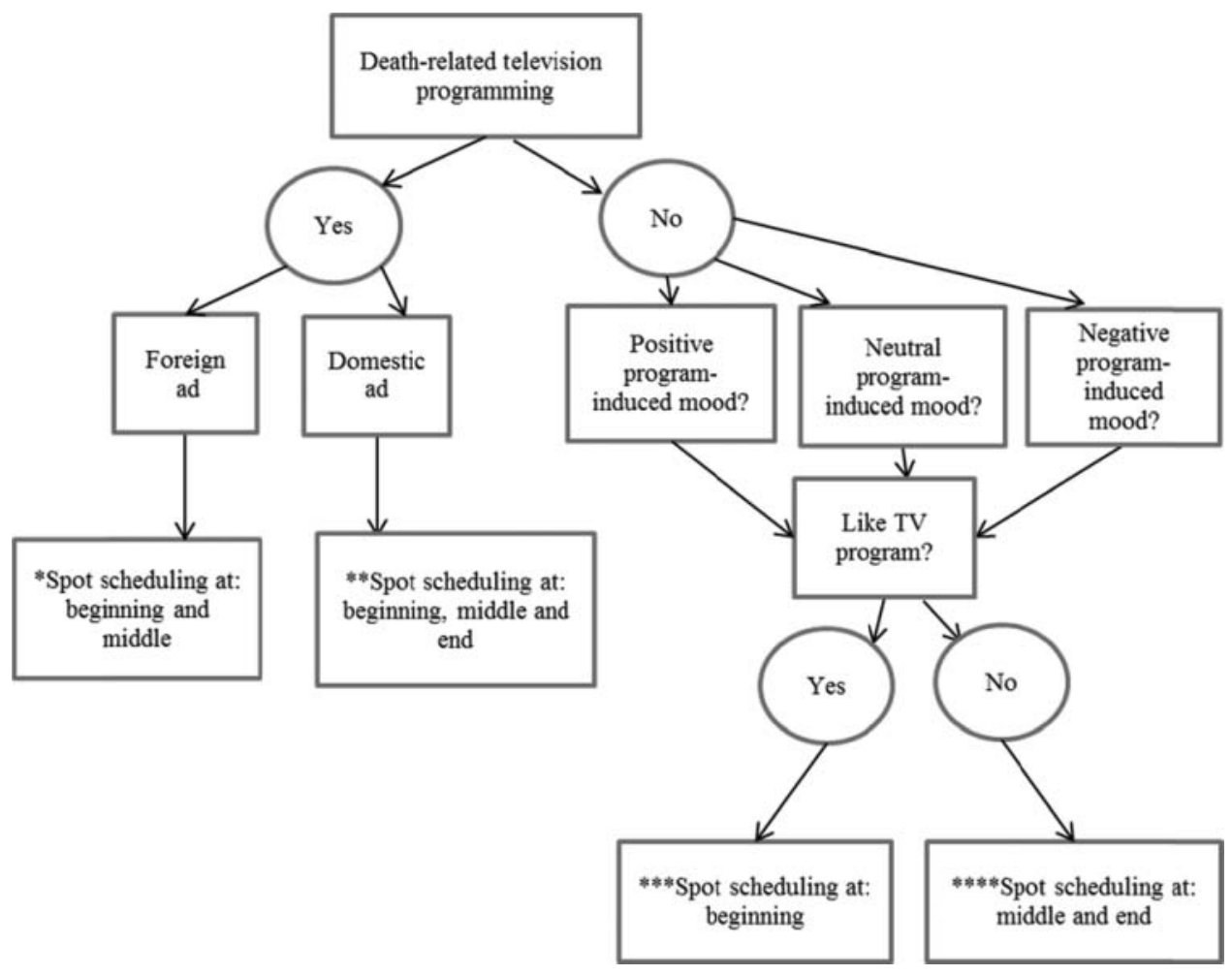

FIG. 2. A framework for scheduling commercials within a pod in a death-related television program context. *A commercial perceived to be foreign is adversely affected toward the end of the pod (Studies 2 and 4). **Domestic ad evaluation is not adversely affected by death-related thoughts in any position. ***Program liking influences the first commercial in the ensuing pod and the effects attenuate for later spot positions (Murry, Lastovicka, and Singh 1992). Positive liking favorably influences the first ad in the ensuing pod. ****If a program is not liked, the adverse influence of negative liking can be attenuated by scheduling spots later in the commercial pod.

introduce a new process variable to program context effects literature, namely, nonconscious death thought accessibility. From a managerial perspective, this research provides direction for both creative execution and media scheduling within the death-related programming framework. Domestic advertisers should highlight the fact that their brand is made in the local country in their communication, while foreign advertisers should ensure that the advertising displays a generous local flavor and minimizes information that alludes to the brand's foreign origin. With regard to media scheduling, advertisers need to be prudent in choosing the spot positions within a pod. Attitude toward the foreign ad declined by more than $15 \%$ after 2.5 minutes of exposure to commercials in the MS (versus control) condition (Studies 2 and 4). Combining our findings with the extant program context research, we propose a commercial scheduling framework in Figure 2.

The limitations of our studies also suggest several areas for future investigation. Program liking and commercial-induced affect were not considered in this study, but these variables could influence MS effects (Murry, Lastovicka, and Singh 1992; Poncin and Derbaix 2009). Moreover, our findings are limited to the United States. It would be prudent to repeat the studies in other countries to rule out country- or culture-specific MS effects, if any. How, for instance, will a commercial for an American product fare in a Chinese MS-inducing TV program? Further, are there other ad contexts wherein MS effects can be observed? Striving for self-esteem is another distal defense against the potential for existential anxiety. Ads for products that promote an enhanced self-concept might be positively, not negatively, influenced toward the end of the pod. Another possibility that merits investigation is whether in a pod the commercials themselves could prime thoughts of death, for example, an ad for life insurance. Addressing these issues will contribute to the nascent MS-inducing television program context literature and will provide advertisers with strategic guidelines for media scheduling.

\section{NOTES}

1. The literature review (refer to online Appendix 1) is specific to television program context's influence on ensuing ad evaluation, not memory or viewer characteristics or other context (e.g., ad context) variables, which are beyond the scope of this research.

2. An in-group consists of three or more people who construe and evaluate themselves in terms of their shared attributes that collectively distinguish them from other people in terms of "we" and "them" (Hogg 2006).

3. We did not attempt to obtain dependent measures in the other MSpod conditions (e.g., after four ads, five ads, six ads) or control 
conditions (e.g., neutral programming followed by filler ads at beginning, middle, and end of pod) as any information gains would have been incremental given the number of participants needed.

4. From a pool of 225 commercials recorded from affiliates in cities away from the study venue, we selected 16 commercials of $30 \mathrm{sec}$ onds duration each for products not available in the study area. In a pretest $(N=40)$ the ads were rated for familiarity and emotionality on a 7-point semantic differential scale $(1=$ Rational/very familiar, 7 = Emotional/very unfamiliar; Law 2002) to minimize any potential confound. Seven ads with an average rationality score of 3 or lower $(M=2.66)$ and an average unfamiliarity score of 4.5 or higher $(M=5.20)$ were selected. Filler ads were randomly chosen for the different studies to prevent confounds due to presentation order.

5. In a pretest $(N=85)$, participants rated interest and familiarity (7point scales) for a range of product categories (e.g., laptop computers) following Gurhan-Canli and Maheswaran (2000). We also obtained ratings on the favorability of country of origin (10-point scale; Maheswaran 1994) and attribute importance (attribute list generated by reviewing popular online portals; 7-point scale; Gurhan-Canli and Maheswaran 2000) for these products. We selected a digital camera as the product category, as it had moderate familiarity $(M=4.56)$ and interest $(M=4.71)$ ratings. We chose the United States and China as the "domestic" and "foreign" nations, respectively, as their favorability ratings on digital cameras were comparable $\left(M_{\mathrm{USA}}=8.42, M_{\mathrm{CHINA}}=7.98 ; t(84)=1.53, p>.1\right)$. Attributes with importance ratings of 5.5 and higher were used to develop two ads for a fictitious brand of digital camera that varied only in the country-of-origin information in the headline.

6. We did not obtain DTA in Study 1, as proximal measures could induce MS and confound results.

7. Using the pretest information from Study 2, two 30-second scratch commercials for the fictitious brand of digital camera were created that varied only in the country-of-origin information in a two-second voiceover at the beginning of the commercial ["... American (versus Chinese) proficiency ..."] and the tagline text ["Made in USA (versus China)"] at the end. During the development stage, comments from participants $(N=22)$ were used to improve the execution of the commercials.

\section{ACKNOWLEDGMENTS}

The authors thank L.J. Shrum and Sanjay Mishra for their feedback and Alex Martynov and Prahalad Rangan for software assistance.

\section{SUPPLEMENTAL DATA}

Supplemental data for this article can be accessed at www.tandfonline.com/ujoa.

\section{REFERENCES}

Arndt, Jamie, John J.B. Allen, and Jeff Greenberg (2001), "Traces of Terror: Subliminal Death Primes and Facial Electromyographic Indices of Affect," Motivation and Emotion, 25 (3), 253-77.
, Jeff Greenberg, Tom Pyszczynski, and Sheldon Solomon (1997), "Subliminal Exposure to Death-Related Stimuli Increases Defense of the Cultural Worldview," Psychological Science, 8 (5), 379-85.

- Sheldon Solomon, Tim Kasser, and Kennon M. Sheldon (2004), "The Urge to Splurge: A Terror Management Account of Materialism and Consumer Behavior," Journal of Consumer Psychology, 14 (3), 198-212.

Aylesworth, Andrew B., and Scott B. MacKenzie (1998), "Context Is the Key: The Effect of Program-Induced Mood on Thoughts about Ad," Journal of Advertising, 27 (2), 17-31.

Broach, V. Carter, Thomas J. Page, and Dale R. Wilson (1995), “Television Programming and Its Influence on Viewers' Perceptions of Commercials: The Role of Program Arousal and Pleasantness," Journal of Advertising, 24 (4), 45-54.

Coulter, Keith S. (1998), "The Effects of Affective Responses to Media Context on Advertising Evaluations," Journal of Advertising, 27 (4), 41-51.

Cunningham, Todd, Amy Shea Hall, and Charles Young (2006), "The Advertising Magnifier Effect: An MTV Study," Journal of Advertising Research, 46 (4), 369-80.

De Pelsmacker, Patrick, Maggie Geuens, and Pascal Anckaert (2002), "Media Context and Advertising Effectiveness: The Role of Context Appreciation and Context/Ad Similarity," Journal of Advertising, 31 (2), 49-61.

Dunnett, Charles, W. (1955), "A Multiple Comparison Procedure for Comparing Several Treatments with a Control," Journal of the American Statistical Association, 50 (272), 1096-121.

Forehand, Mark R., and Rohit Deshpande (2001), "What We See Makes Us Who We Are: Priming Ethnic Self-Awareness and Advertising Response," Journal of Marketing Research, 38 (3), 336-48.

Goldberg, Marvin E., and Gerald G. Gorn (1987), "Happy and Sad TV Programs: How They Affect Reactions to Commercials," Journal of Consumer Research, 14 (3), 387-403.

Grabe, Maria E., Annie Lang, Shuhua Zhou, and Paul David Bolls (2000), "Cognitive Access to Negatively Arousing News An Experimental Investigation of the Knowledge Gap," Communication Research, 27 (1), 3-26.

Greenberg, Jeff, Tom Pyszczynski, Sheldon Solomon, Elizabeth Pinel, Linda Simon, and Krista Jordan (1993), "Effects of Self-Esteem on Vulnerability-Denying Defensive Distortions: Further Evidence of an Anxiety-Buffering Function of Self-Esteem," Journal of Experimental Social Psychology, 29 (3), 229-51.

— Andy Martens, Eva Jones, Donna Eisenstadt, Tom Pyszczynski, and Sheldon Solomon (2003), "Psychological Defense in Anticipation of Anxiety: Eliminating the Potential for Anxiety Eliminates the Effect of Mortality Salience on Worldview Defense," Psychological Science, 14 (5), 516-19.

— Tom Pyszczynski, and Sheldon Solomon (1986), "The Causes and Consequences of a Need for Self-Esteem: A Terror Management Theory," in Public Self and Private Self, R.F. Baumeister, ed., New York: SpringerVerlag, 189-212.

, Linda Simon, Tom Pyszczynski, and Sheldon Solomon (2000), "Proximal and Distal Defenses in Response to Reminders of One's Mortality: Evidence of a Temporal Sequence," Personality and Social Psychology Bulletin, 26 (1), 91-99.

- Sheldon Solomon, Linda Simon, and Michael Breus (1994), "Role of Consciousness and Accessibility of Death-Related Thoughts in Mortality Salience Effects," Journal of Personality and Social Psychology, 67 (4), 627-37.

Griskevicius, Vladas, Noah J. Golstein, Chad R. Mortensen, Jill M. Sundie, Robert B. Cialdini, and Douglas T. Kenrick (2009), "Fear and Loving in Las Vegas: Evolution, Emotion, and Persuasion," Journal of Marketing Research, 46 (3), 384-95.

Gurhan-Canli, Zeynep, and Durairaj Maheswaran (2000), "Cultural Variations in Country of Origin Effects," Journal of Marketing Research, 37 (3), 309-17.

Hayes, Andrew F., Kristopher J. Preacher, and Teresa A. Myers (2010), "Mediation and the Estimation of Indirect Effects in Political 
Communication Research," in Sourcebook for Political Communication Research: Methods, Measures, and Analytical Techniques, E.P. Bucy and R. Lance Holbert, eds., New York: Routledge, 434-65.

Hayes, Joseph, Jeff Schimel, Jamie Arndt, and Erik, H. Faucher (2010), “A Theoretical and Empirical Review of the Death-Thought Accessibility Concept in Terror Management Research," Psychological Bulletin, 136 (5), 699-739.

Hogg, Michael A. (2006), "Social Identity Theory," in Contemporary Social Psychological Theories, P.J. Burke, ed., Stanford, CA: Stanford University Press, 111-36.

Kamins, Michael A., Lawrence J. Marks, and Deborah Skinner (1991), "Television Commercial Evaluation in the Context of Program-Induced Mood: Congruency versus Consistency Effects," Journal of Advertising, 20 (2), 1-14.

Krugman, Herbert E. (1983), "Television Program Interest and Commercial Interruption," Journal of Advertising Research, 23 (1), 21-23.

Lang, Annie, Robert F. Potter, and Paul D. Bolls (1999), "Something for Nothing: Is Visual Encoding Automatic?," Media Psychology, 1 (2), 145-63.

LaTour, Michael S., and Herbert J. Rotfeld (1997), "There Are Threats and (Maybe) Fear-Caused Arousal: Theory and Confusions of Appeals to Fear and Fear Arousal Itself," Journal of Advertising, 26 (3), 45-59.

Law, Sharmistha (2002), "Can Repeating a Brand Claim Lead to Memory Confusion? The Effects of Claim Similarity and Concurrent Repetition," Journal of Marketing Research, 39 (3), 366-78.

Liu, Jia, and Dirk Smeesters (2010), "Have You Seen the News Today? The Effect of Death-Related Media Contexts on Brand Preferences," Journal of Marketing Research, 47 (2), 251-62.

Lloyd, David W., and Kevin J. Clancy (1991), "CPMs versus CPMIs: Implications for Media Planning," Journal of Advertising Research, 31 (4), 34-44.

Maheswaran, Durairaj (1994), "Country of Origin as a Stereotype: Effects of Consumer Expertise and Attribute Strength on Product Evaluations," Journal of Consumer Research, 21 (2), 354-65.

Murry, John P., and Peter A. Dacin (1996), "Cognitive Moderators of Negative Emotion Effects: Implications for Understanding Media Contexts," Journal of Consumer Research, 22 (4), 439-47.

, John L. Lastovicka, and Surendra N. Singh (1992), "Feeling and Liking Responses to Television Programs: An Examination of Two Explanations for Media-Context Effects," Journal of Consumer Research, 18 (4), $441-51$.
Parents Television Council (2013), Media Violence Special Report, http://w2. parentstv.org/main/Research/Reports.aspx.

Poncin, Ingrid, and Christian Derbaix (2009), "Commercials as Context for Other Commercials: Threat or Opportunity?," Journal of Advertising, 38 (3), 33-49.

Potter, Robert F., Michael S. LaTour, Kathryn A. Braun-LaTour, and Tom Reichert (2006), "The Impact of Program Context on Motivational System Activation and Subsequent Effects on Processing a Fear Appeal," Journal of Advertising, 35 (3), 67-80.

Preacher, Kristopher, J., and Andrew F. Hayes (2004), "SPSS and SAS Procedures for Estimating Indirect Effects in Simple Mediation Models," Behavior Research Methods, Instruments, and Computers, 36 (4), $717-31$.

— Derek D. Rucker, and Andrew F. Hayes (2007), "Assessing Moderated Mediation Hypotheses: Theory, Methods, and Prescriptions," Multivariate Behavioral Research, 42 (1), 185-227.

Pyszczynski, Tom, Jeff Greenberg, and Sheldon Solomon (1999), “A DualProcess Model of Defense against Conscious and Unconscious DeathRelated Thoughts: An Extension of Terror Management Theory," Psychological Review, 106 (4), 835-45.

— $\longrightarrow$, and - (2005), "The Machine in the Ghost: A Dual-Process Model of Defense against Conscious and Unconscious Death-Related Thought," in Social Motivation: Conscious and Unconscious Processes, J. Forgas, W.D. Kipling, and S.M. Laham, eds., New York: Cambridge University Press, 40-54.

Shapiro, Stewart, Deborah J. MacInnis, and C. Whan Park (2002), "Understanding Program-Induced Mood Effects: Decoupling Arousal from Valence," Journal of Advertising, 31 (4), 15-26.

State of the News Media (2013), Pew Research Center, http://stateofthemedia. org/.

Swaminathan, Vanitha, Karen L. Page, and Zeynep Gurhan-Canli (2007), “'My' Brand or 'Our' Brand: The Effects of Brand Relationship Dimensions and Self-Construal on Brand Evaluations," Journal of Consumer Research, 34 (2), 248-58.

Tavassoli, Nader T., Clifford J. Shultz, and Gavin J. Fitzsimons (1995), "Program Involvement: Are Moderate Levels Best for Ad memory and Attitude toward the Ad?," Journal of Advertising Research, 35 (5), 51-61.

Watson, D., Lee A. Clark, and Auke Tellegen (1988), "Development and Validation of Brief Measures of Positive and Negative Affect: The PANAS Scale," Journal of Personality and Social Psychology, 53, 1063-70. 